\title{
Morphometry and Histology of the Gastrointestinal Organs of the African White Breasted Hedgehog (Atelerix albiventris)
}

\section{Alhaji Zubair Jaji ${ }^{1}$, Joseph Jesunifemi Akano, Shaibu. Mo- hammed. Atabo ${ }^{2}$, Kenechukwu Tobechukwu Onwuama ${ }^{1}$, Es- ther Solomon Kigir ${ }^{1}$, AbdulMajeed Ishiaku³, Adegboye Adiru Afolabi ${ }^{4}$, Sulaiman Olawoye Salami ${ }^{1}$.}

\begin{abstract}
${ }^{1}$ Department of Veterinary Anatomy, Faculty of Veterinary Medicine, University of Ilorin, Ilorin, Nigeria.

${ }^{2}$ Department of Animal Health and Production College of Agriculture and Animal Science, P.M.B 1022, Bakura, Sokoto state.

${ }^{3}$ Department of Veterinary Pathology, Faculty of Veterinary Medicine, University of Ilorin, Ilorin, Nigeria.

${ }^{4}$ Department of Veterinary Medicine, Faculty of Veterinary Medicine, University of Ilorin, Ilorin, Nigeria.
\end{abstract}

Received September, accepted for publication October 2019

\section{Abstract}

Morphometric studies were carried out on organs of the gastrointestinal tract (GIT) of African white breasted Hedgehog obtained from local markets in llorin metropolis $\left(8.4882^{\circ} \mathrm{N}\right.$, $\left.4.5341^{\circ} \mathrm{E}\right)$, Ilorin, Nigeria. Ten (10) hedgehogs were used. The animals were euthanized and GIT organs were exteriorized for gross morphometric studies' Tissue samples were collected from the GIT segments, processed using the routine paraffin method and stained using the Hematoxylin \& Eosin stain. This study observed a remarkable conformational difference between the male and female African white breasted Hedgehog, with the female having significantly larger body weight, tongue and gastrointestinal biometry as compared J. Vet. Anat. to the males. Its stomach was a C shaped saccular sac. The intestines were straight and cylindrical, except the jejunum which was tortuous. The large intestine had a colon but lacked a caecum. Histologically, the esophagus, stomach, duodenum, jejunum and colon all had four layers: mucosae, submucosae, muscularis and serosa. The esophageal mucosae had keratinized stratified squamous epithelium. The duodenal and jejunal mucosae had villi and crypts of Lieberkuhn, lined with simple columnar epithelium. Villi were absent in the colon. Mucosal glands were seen in the stomach but were absent in the other parts of the GIT. The tunica muscularis in all the segments of the GIT had inner circular, middle oblique and outer longitudinal smooth mus-

Vol. 12, No. 2, (2019) 1 - 14 
cles, except the esophagus which had only inner circular and outer longitudinal layers. It was concluded that with the exception of the caecum, the GIT of the African white breasted Hedgehog is grossly relatively similar to those of other monogastric mammals and shows Histomorphologic variations across its component organs. Thus, further Histochemical and Immunohistochemical analyses of the organs are recommended.

Keywords: African white breasted Hedgehog, Histomorphology, Duodenum, Jejunum, Colon

\section{Introduction}

Hedgehogs are mammals with spiny protection which resembles that of the unrelated porcupines, which are rodents, and echidnas, a type of monotreme (Nijman and Bergin, 2015). Hedgehogs are omnivorous animals that feed on mushrooms, grass roots, berries, melons and watermelons, insects, snails, frogs, snakes, bird and eggs (Qumsiyeh, 1996). The hedgehog has a muscular and mobile tongue that occupies the major part of the oral cavity and part of the oropharynx. Its main functions are pushing food into the oropharynx during swallowing and forming words during vocalization, although it is also implicated in mastication, taste, and oral cleansing (Qumsiyeh, 1996). Hedgehog possess a simple stomach and lack a caecum. Gastrointestinal transit time is $12-16$ hours (Ivey and Carpenter, 2004).

Hedgehogs are used to treat several ailments. The blood is sold as a cure for ringworm, cracked skin and warts and the flesh is eaten as a remedy for witchcraft (Nijman and Bergin, 2015). Romani people still eat hedgehogs, boiled or roasted, and also use the blood and the fat for its supposed medicinal value (Wood, 1979).

Adeniyi (2010) reported the morphometry of the tongue and dentition in the African white breasted Hedgehog (Atelerix albiventris). However, the morphometry and histology of the GIT in the African white breasted Hedgehog is yet to be documented, hence this study was conducted with the aim of documenting relevant information on the morphometry and histology of the gastrointestinal organs of the African white breasted hedgehog (Atelerix albiventris).

\section{Material and Methods}

The studies were approved by the Institutional Animal Care and Use Committee (IACUC), University of Ilorin, Nigeria (Ref.: FVERC/W0Q9/ 11). Apparently healthy African white breasted Hedgehogs were procured from local markets within the llorin metropolis $\left(8.4882^{\circ} \mathrm{N}, 4.5341^{\circ} \mathrm{E}\right)$, Ilorin, Nigeria for the study. They were kept in the Animals Housing Facility, Faculty of Veterinary Medicine, University of Ilorin, Nigeria. They were 
Gastrointestinal organs of the African Hedgehog Jaji et al.,

maintained at constant temperature, with 12-hour light/12-hour dark cycles and provided with feed (pap and egg albumen) and water ad libitum for a week before the day of the study.

The early part of the experiment was carried out at the Veterinary Gross Anatomy Laboratory, Faculty of Veterinary Medicine, University of Ilorin, Nigeria. A total of ten Hedgehogs were used in this study. The animals were euthanized with thiopental sodium $(150 \mathrm{mg} / \mathrm{kg} \mathrm{i} / \mathrm{p})$. After euthanasia, each animal was weighed in grams (g) using the GF-300 Analytical Balance $310 \times 0.001 \mathrm{~g}$, AND A\&D Weighing, India, and dissected with the scalpel and blades and forceps. The in situ positions of the tongue and the gastrointestinal organs (esophagus, stomach, duodenum, jejunum, ileum and colon) were noted and photographed, using a Sony digital camera. Next, the organs were exteriorized for morphologic and morphometric (biometric) studies. The following biometry were measured using ribbons, threads, tape rule, ruler and digital Vernier caliper.

1. Tongue biometry

a. Tongue Length $(\mathrm{TL})(\mathrm{cm})$

b. Tongue Apical Breadth (TAB) (cm)

c. Tongue Body Breadth (TBB) (cm)

d. Tongue Root Breadth (TRB) (cm)

2. Esophageal length $(\mathrm{OL})(\mathrm{cm})$

3. Duodenal length $(\mathrm{DL})(\mathrm{cm})$
4. Jejunal length $(\mathrm{JL})(\mathrm{cm})$

5. Ileal length (IL) $(\mathrm{cm})$

6. Colonal length $(\mathrm{CL})(\mathrm{cm})$

One cubic centimeter, of histologic samples were taken from each organ/structure and fixed in $10 \%$ buffered formaldehyde solution in a universal sample bottle and labelled. These bottles were afterwards sent to the Veterinary Histology Laboratory of the faculty for histological processing into histologic slides using the routine Paraffin method, and for staining using the Hematoxylin and Eosin staining technique. The histological slides of the esophagus and intestines were studied under the Olympus camera mounted microscope and relevant micrographs taken thereof at $\times 40$ magnification.

\section{Statistical Analyses}

Descriptive (mean \pm standard deviation) statistics of the dimensions were carried out using the Microsoft Excel worksheet (Microsoft Office 2013 software, Microsoft(C) and the Student T-test was used to determine the statistical significance of any differences between female and male values using GraphPad Prism version 5.00 (GraphPad Software, San Diego California USA) at $p<0.05$

\section{Results \\ Morphology}

The in situ arrangement of the digestive system of the hedgehog bears resemblance with those of other mo- 
nogastric mammals (Fig 1). Its oral cavity contained the tongue, teeth and other accessory digestive organs. The tongues were highly vascularized and had a rostral tapering apical part. The lingual apex was continuous with the body, a wider middle part and ended at the root, the widest part of the tongue (Figs 2 and 3). The oral cavity was continuous with the oropharynx, which connected it to the esophagus, a long musculoelastic cylindrical tube (Fig 3). This tube was located dorsal to the trachea; extended the whole length of the neck and ended at the stomach, after passing through the esophageal hiatus of the diaphragm. The incursion of the convex part of the diaphragm into the caudal part of the thorax enabled a cranial extension of the abdominal cavity into the thoracic cavity. This extended part bore the liver and parts of the stomach and small intestines (Fig 1). The convex (parietal) part of the liver was in contact with the concave part of the diaphragm while its concave (visceral) part was in contact with other visceral organs. The remaining parts of the digestive tract were located in the abdominal cavity. Its stomach was a C shaped saccular sac that connected with the esophagus cranially and duodenum caudally. The intestines were straight and cylindrical, except the jejunum which was tortuous (Fig 3). The large intestine had a colon but lacked a caecum.

\section{Morphometry}

The mean body weight and biometry of tongue and intestines of the female African white breasted Hedgehog were significantly higher $(p<0.05)$ as compared to males (Table 1 and Table 2).

\section{Histology}

The histology of the intestines of the African white breasted Hedgehog (Atelerix albiventris) showed regional variations in the histology of various parts studied (Figs $4-8$ ).

\section{Discussion}

This study observed a remarkable conformational difference between the male and female African white breasted Hedgehog, with the female having larger body size and weight than the males. The overall mean weight reported in this study was lower than that reported by Adeniyi (2010) and Girgiri et al. (2015) who recorded $210.00 \pm 11.03 \mathrm{~g}$ and $239.5 \pm 28.3 \mathrm{~g}$ respectively. Girgiri et al. (2015) further stated that there was no significant difference in the body weight of both sexes of African Hedgehog, arguing that these variations could be due to the differences in age, feeding and the ecology of the animals (Rahman and Sharma, 2014). Joseph (1908) also reported a significantly higher body weight in the male dog, cat, rabbit and guinea pig compared to the females. Special attention is currently being given to morphometrical analysis of sexual dimorphism (Rahman and Sharma, 2014).

\footnotetext{
J. Vet. Anat.
} 
The tongue of the African white breasted Hedgehog was a muscular organ with apex, body and root occupying the major part of the oral cavity proper. This was in agreement with report of Jabbar (2014) and Parchami et al. (2018), who further reported that the tongue in the long-eared hedgehog (Hemiechinus auritus) is an elongated and rectangular shaped body with widened root and a marked deep median groove on its dorsal surface, with two huge laterally situated folds on the lingual root. Which were consistent with our observations this present study. The average lingual length, apical, body and root breadth in females were found to be statistically higher than those of the males $(p<0.05)$. The overall mean lingual length in this investigation (3.34 \pm $0.52 \mathrm{~cm}$ ) was closely similar to those reported by Adeniyi (2010), Jabbar (2014) and Parchami et al. (2018) who reported $3.10 \mathrm{~cm}$ (in the African hedgehog), $2.45 \mathrm{~cm}$ (in the Iraqi hedgehog) and $2.7 \mathrm{~cm}$ (in the Longeared hedgehog) respectively.

The gastrointestinal tract of the African white breasted Hedgehog of this present study was observed to be a collection of related anatomical structures that were serially connected. They included the esophagus, simple stomach and the intestines, without caecum. This arrangement aids in the digestion of food and processing of nutrients. (Ivey and Carpenter, 2004; Johnson-Delany 2006). Morphometri- cally, the African white chested hedgehog had gender specific variation in the lengths of its esophagus, duodenum, jejunum, ileum, and colon. The female hedgehogs had a longer and better developed gastrointestinal tract compared to the male hedgehog, except in few individuals where some structures tallied. The European hedgehog is better developed than the African hedgehog in weight and every other related structure (Girgiri et al., 2015).

Histologically, the esophagus of the African white breasted Hedgehog is a muscular tube through which the pharynx connects with the stomach. It has a stratified squamous keratinized epithelium with a lamina propria, muscularis mucosa, submucosal mucous gland and basal cell layers adapted for transport of food from pharynx to the stomach. It has been reported that degree of esophageal keratinization depends on the diet of the animals (Johnson-Delaney, 2005); the high level of esophageal keratinization observed in this study is similar to that of ruminants and this could be due to the wide variety of feeding habits by the animal (Rahman and Sharma, 2014). This finding is consistent with previous studies suggesting high keratinization of esophageal mucosal epithelium (Chen et al., 2008), serving to protects underlying tissues from mechanical damage and entry of microorganisms present in 
the oropharynx (Squier and Kremer, 2001).

Although, the esophageal epithelial lining in Hedgehog is similar to that of animals but it is also known that some species are different and lined with columnar epithelium (Ahmed et al., 2009). The muscularis externa contains largely skeletal muscles and a few smooth muscles adapted for rapid passage of food from pharynx to stomach (Meyer et al., 2014).

Similar to rats (Ghoshal and Bal, 1989) and mice (Haschek et al., 2010), the stomach had gastric pits and mucosal glands on gastric folds. The stomach has folds or ridges called rugae; gastric glands; gastric pits, a secretory sheath with its muscularis mucosae, chief cells and parietal cells, the gastric glands secretes gastric juice and mucus to enhance digestion and protects the stomach lining respectively (Aspinall and Cappello, 2009). The rugae in the inner layer of the stomach (mucosa) allow the stomach and other tissues to expand in order to accommodate large meals and help to grip and move food during digestion (Haschek et al., 2010). Submucosa, muscularis and serosa layers were all present. The submucosa was made up of various connective tissues which supported and connected the muscularis layer. The muscularis consisted of three layers of muscle tissues which allowed the stomach to contract, mix and propel food through the digestive tract. The serosa was a serous membrane made of simple squamous epithelium and areolar connective tissue, it helps to protect the stomach from friction. These features were consistent with earlier studies by Aspinall and Cappello (2009) in monogastric domestic animals.

The duodenum of the African white breasted Hedgehog of the present study was lined by mucosa, submucosa, muscularis and adventitia. However, unlike in rats (Umoren and Osim, 2014), its submucosa was devoid of Brunner's glands. In contrast to the previous observation, the mucosae in both animals are characterized by villi, crypts of Lieberkuhn and ducts. As in other animals, the crypts are found between the villi and their cells (Paneth cells) secrete intestinal juice (anti-microbial peptides) which are shed into the intestinal lumen which further digest polypeptides into amino acids (Saladin, 2004).

The jejunum, as in other animals, was comprised of mucosa, submucosa, muscularis externa and serosa (Umoren and Osim, 2014), similar to rats (Zhimin et al., 2015), the jejuna mucosa had a plicae circulares, villi and crypts, however, they were more conspicuous in the Hedgehog. The cells in the mucosal layer produce mucus for lubrication and protection to assist in the absorption of nutrient (Omotoso et al., 2012). 
The colon has only crypts of Lieberkuhn, devoid of villi. The mucosa layer is smooth and the cells of the crypts of Lieberkuhn secrete intestinal juice into the lumen of the intestines (Akers and Denbow, 2013). The findings on colon in this study agree with the work of Erman (1998) and Umoren and Osim (2014) who states that the colon in animals is lined by simple columnar epithelium with numerous goblet cells. The colon function to collect fluid, electrolytes and undigested food. It has a prominent lamina propria and crypts of Lieberkuhn.

The study has provided a baseline data on the Morphometry and histomorphology of the GIT of the African white breasted Hedgehog found in llorin, Nigeria for comparative anatomical studies of wild and captive small animals, and may be applicable in the field of studies. It is recommended that further histochemical and Immunohistochemical analyses of the studied organs be carried out, towards further documentation of information on this aspect.

\section{Conclusion and Recom- mendations}

The study observed that the morphometry differs in other genera and species of hedgehogs, rodents and between sexes. The morphology appears the same with other genera and species of hedgehogs except those rodents that have the presence of a caecum (Nzalak et al., 2012). It was J. Vet. Anat. concluded that with the exception of the caecum, the GIT of the African white breasted Hedgehog is grossly and histologically similar to those of other monogastric animals and shows Histomorphologic variations across its component organs. Thus, further Histochemical and Immunohistochemical analyses of the organs are recommended, for more documentation of information on this aspect.

\section{Acknowledgment}

Our appreciations go to the Department of Veterinary Anatomy and the Faculty of Veterinary Medicine, University of Ilorin, Nigeria for serving as the impetuses towards the successful conduct of this study.

\section{Competing Interest}

Authors have declared that no competing interests exist.

\section{References}

Adeniyi, P.A.O. (2010): Morphometric analysis of tongue and dentition in hedgehogs and pangolins. Eur J Anat, 14(3): 149-152.

Ahmed, Y.A., EI-Hafez, A.A.E. and Zayed, A.E. (2009): Histological and Histochemical Studies on the Esophagus, Stomach and Small Intestines of Vara-nus niloticus. J. Vet. Anat. 2(1): $35-48$.

Akers, R.M. and Denbow, D.M. (2013): Anatomy and Physiology of Domestic Animals $2^{\text {nd }}$ Edition John Wiley \& Sons lowa, USA. 94p. 
Aspinall, V. and Cappello, M. (2009): Introduction to Veterinary Anatomy and Physiology textbook $2^{\text {nd }}$ edition. Elsevier. 70-71p.

Chen, X., Qin. R and Shaheen, N. (2008): Multilayered epithelium in a rat model and human Barret's oesophagus: Similar expression patterns of transcription factors and differentiation markers. BMC Gastroenterol. 8(1): 1-9,

Dyce, K.M., Sack, W.O. and Wensing, C.J.G. (2010): Textbook of Veterinary Anatomy 4th edition. Saunders Elsevier Inc. US, P102.

Elliott, J.R. (2007): Overview of Reptile Biology, Anatomy, and Histology. Infectious Diseases and Pathology of Reptiles. Elliott. J. R. Brooklyn, New York, Taylor \& Francis Group. 1-25p.

Erman, L., Mingli, W. and Liping, W. A (1998): Histomorphological Study on Digestive System of Adult Hedgehog. Journal of Forestry Research, 9(2): 111-114

Ghoshal, N.G. and Bal, H.S. (1989): Comparative morphology of the stomach of some laboratory mammals. Laboratory Animals. 23: 21-29.

Girgiri, I. A., Gambo, B. G., Ibrahim, B. and Bwala, A. (2015): Morphometric studies of some visceral organs and gastrointestinal tract of fourtoed african hedgehog (atelerix albiventris). J. Morphol. Sci., 32(1): 2932.

Haschek, W.M., Rousseaux, C.G. and Wallig, M.A. (2010): Fundamen- tals of toxicologic pathology: Gastrointestinal Tract 2nd edition Elsevier.163-196p.

Ivey, E. and Carpenter, JW. (2004): African hedgehogs: Ferrets, Rabbits and Rodents Clinical Medicine and Surgery. $2^{\text {nd }}$ ed. St. Louis, MO: Saunders, 339-353p.

Jabbar, A.I. (2014): Anatomical and Histological Study of Tongue in the Hedgehog (Hemiechinus Auritus). International Journal of Recent Scientific Research 5(4): 760-763.

Johnson-Delaney, C.A. (2005): The ferret gastrointestinal tract and Helicobcter mustelae infection. Vet. Clin North Am Exotic Anim Pract., 8:197212.

Johnson-Delany, C.A. (2006): Anatomy and physiology of the gastrointestinal system of the ferret and selected exotic carnivores. In Proceedings from the association of avian veterinarians. p. 29-38.

Joseph, D.R. (1908): The ratio between the heart-weight and bodyweight in various animals Journal of experimental medicine 10(4): 521528.

Kumar, K.V. (2011): Gest, Thomas R. (ed.). "Large Intestine Anatomy". Medscape. WebMD LLC. Retrieved 2013-08-20.

Meyer, W., Schoennagel, B., Kacza, J., Busche, R., Hornickel, I.N., Hewicker-Trautwein, M. and SCnapper, A. (2014): Keratinzation of the esophageal epithelium of do- 
mestic mammals. Acta Histochemica. 116(1): 235-242.

Nijman, V. and Bergin, D. (2015):"Trade in hedgehogs (Mammalia: Erinaceidae) in Morocco, with an overview of their trade for medicinal purposes throughout Africa and Eurasia". Journal of Threatened Taxa. 7(5): $\quad 7131-7137 . \quad$ doi :0.11609/JoTT.04271.7131-7.

Nzalak, J.O., Onyeanusi, B.I. and Salami, S.O. (2012): Macrometric study of the digestive system of the African giant rat (Cricetomys gambianus Waterhouse 184. European Journal of Anatomy, vol. 16, p. 113118.

Omotoso G.O, Muonagolu J.N, Enaibe, B.U. (2012): Histological evaluation of the jejunum and ileum of rats after administration of high dose garlic aqueous extract. International Journal of Health Sciences, 6(2): 135140

Parchami, A., Salimi, M. and Khosravi, M. (2018): Tongue structure in the long-eared hedgehog (Hemiechinus auritus): A scanning electron microscopic study. Veterinary Research Forum 9(3): 205-209.

Qumsiyeh, M.B. (1996): Mammals of the Holy Land. Texas Tech UP. p. 64.
Rahman, M.S., and Sharma D.K. (2014): Morphometric, Anatomical and histological features of Gastrointestinal Tract (GIT) of Freshwater Turtle, Pangshura tentoria International Journal of Scientific \& Engineering Research, 5(7): 90-94.

Saladin, K.S. (2004): Anatomy and physiology: the unity of form and function, $3^{\text {rd }}$ edition. McGraw-Hill companies, Inc., 1221 Avenue of Americas, New York. 35p.

Squier, C.A. and Kremer, M.J. (2001): Biology of oral mucosa and esophagus. J. Natl. Cancer Inst. Monogr. 29: 7-15.

Umoren, E.B. and Osim, E.E. (2014): Morphology of the small intestine of Albino Wistar Rats following long term administration of nevirapine. Biochem. Pharmacol. 3(2): 1-5 doi: 10.4172/2167-0501.1000132.

Wood, M.F. (1979): In the Life of a Romany Gypsy. J.A. Brune. 80-81p ISBN 978-0-7100-0197-9.

Zhimin, W., Weng-Lang, Y., Asha, V., Monowar, A. and Ping, W. (2015): Human Ghrelin mitigates intestinal injury and mortality after whole body irradiation in rats. PloS one 10: e011821.

Corresponding author: mohakosh@yahoo.com 
Table 1: Mean \pm Standard Deviation of the Tongue biometry of the African White Breasted Hedgehog (Atelerix Albiventris).

\begin{tabular}{lccc}
\hline $\begin{array}{l}\text { Tongue biometry } \\
(\mathbf{c m})\end{array}$ & Male & Female & Overall mean \\
\hline Length & $2.97 \pm 0.83^{\mathrm{a}}$ & $3.70 \pm 0.26^{\mathrm{b}}$ & $3.34 \pm 0.52$ \\
Apical breadth & $0.50 \pm 0.10^{\mathrm{a}}$ & $0.73 \pm 0.15^{\mathrm{b}}$ & $0.62 \pm 0.16$ \\
Body breadth & $0.73 \pm 0.12^{\mathrm{a}}$ & $1.10 \pm 0.20^{\mathrm{b}}$ & $0.92 \pm 0.26$ \\
Root breadth & $1.13 \pm 0.21^{\mathrm{a}}$ & $1.60 \pm 0.20^{\mathrm{b}}$ & $1.37 \pm 0.33$ \\
\hline
\end{tabular}

${ }^{\mathrm{ab}}$ Means with different superscripts across the rows differs significantly at $<0.05$

Table 2: Mean \pm Standard Deviation of the body weight and biometry of the organs of the gastrointestinal tract in African White Breasted Hedgehog (Atelerix Albiventris).

\begin{tabular}{llll}
\hline Biometry & Male & Female & Overall mean \\
\hline Body Weights $(\mathrm{g})$ & $157.00 \pm 27.87^{\mathrm{a}}$ & $248.67 \pm 12.66^{\mathrm{b}}$ & $202.84 \pm 64.82$ \\
Oesophageal length $(\mathrm{cm})$ & $6.00 \pm 0.30^{\mathrm{a}}$ & $9.50 \pm 2.78^{\mathrm{b}}$ & $7.75 \pm 2.47$ \\
Duodenal length $(\mathrm{cm})$ & $5.83 \pm 0.38^{\mathrm{a}}$ & $7.17 \pm 1.04^{\mathrm{b}}$ & $6.5 \pm 0.95$ \\
Jejunal length $(\mathrm{cm})$ & $58.67 \pm 4.16^{\mathrm{a}}$ & $70.00 \pm 4.58^{\mathrm{b}}$ & $64.34 \pm 8.01$ \\
lleal length $(\mathrm{cm})$ & $8.53 \pm 0.47^{\mathrm{a}}$ & $12.83 \pm 2.57^{\mathrm{b}}$ & $10.68 \pm 3.04$ \\
Colonal length $(\mathrm{cm})$ & $4.97 \pm 0.15^{\mathrm{a}}$ & $5.93 \pm 0.93^{\mathrm{b}}$ & $5.45 \pm 0.68$ \\
\hline
\end{tabular}

${ }^{\mathrm{ab}}$ Means with different superscripts across the rows differs significantly at $<0.05$

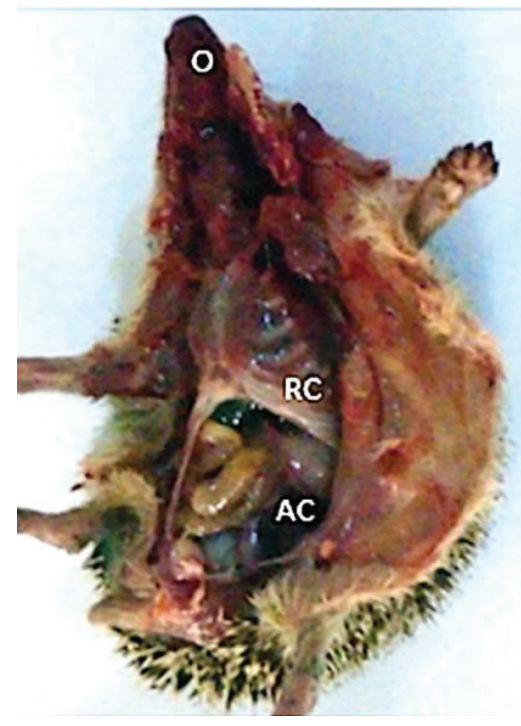

A

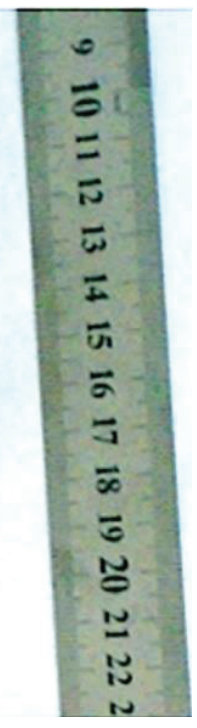

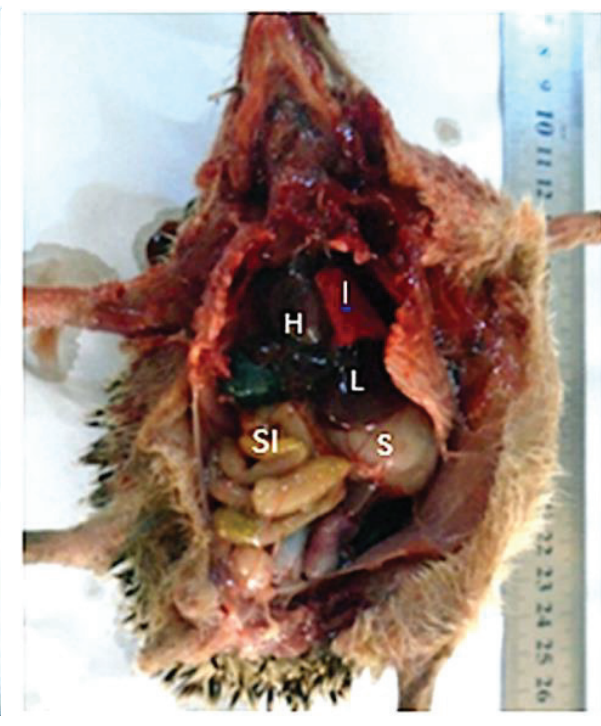

B

Fig (1): Photograph depicting the locations of its oral cavity and the gastrointestinal (GIT) organs and associated organs of the white breasted Hedgehog (Atelerix albiventris). (A) The liver and part of the stomach and small intestines were located in the thoracic cage, bounded by the rib cage, RC. The reminder of the GIT (intestines) were located in the abdominal cavity (AC). (B) The thoracic cage has been opened to expose the lungs $(\mathrm{I})$, heart $(\mathrm{H})$, liver $(\mathrm{L})$ and parts of stomach $(\mathrm{S})$ and small intestines (SI it enclosed.

J. Vet. Anat. 


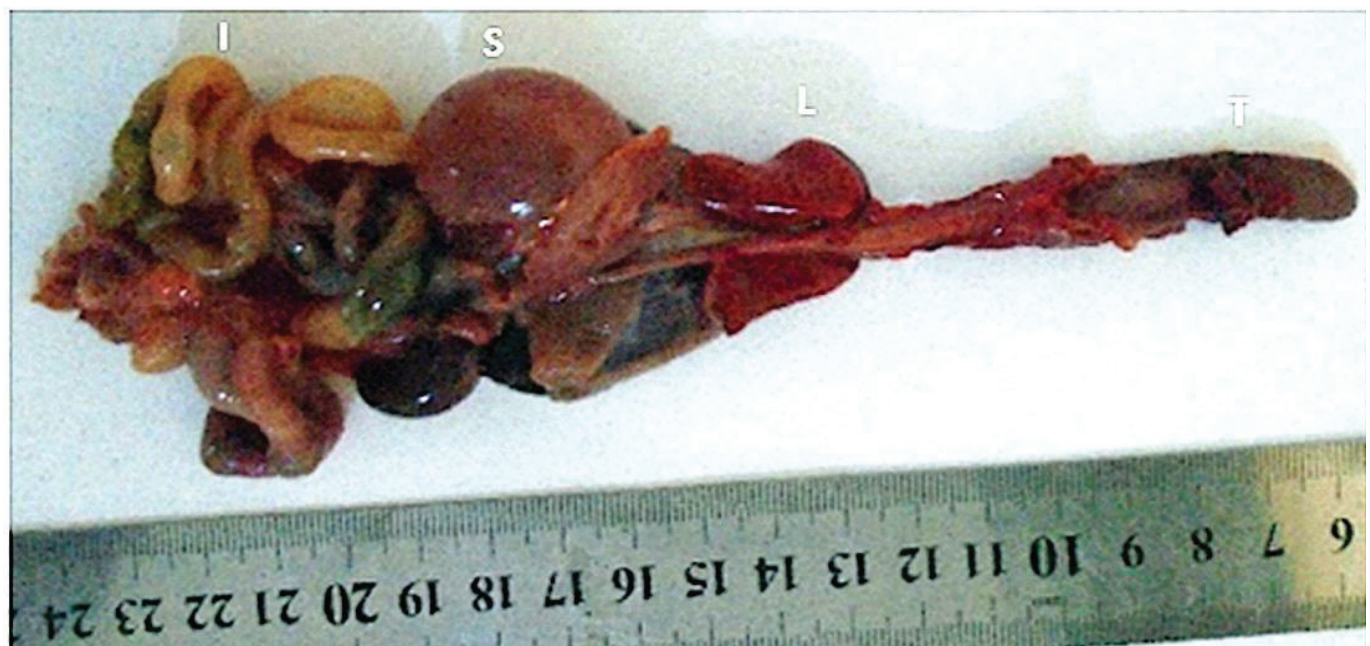

Fig (2): Photograph of the parts of the pluck (tongue (T) and lungs (L)) and the gastrointestinal tract (stomach (S) and small and large intestines (I)) of the white breasted Hedgehog (Atelerix albiventris) after evisceration.

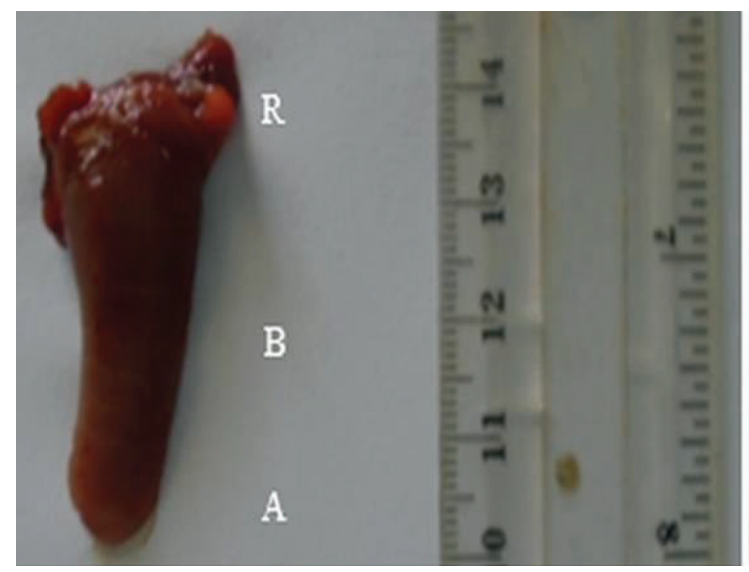

\section{A}

Fig (3): Photographs of the white breasted Hedgehog (Atelerix albiventris) tongue and gastrointestinal tract. (A) Shows the Tongue and its apex (A), body (B) and root (R); (B) shows the pluck $(P)$ and the gastrointestinal tract (oesophagus $(\mathrm{Oe})$, stomach $(\mathrm{S})$, duodenum and the pancreas (DP), jejunum (J) ileum (I), colon (C) and anus (A)) after evisceration. 


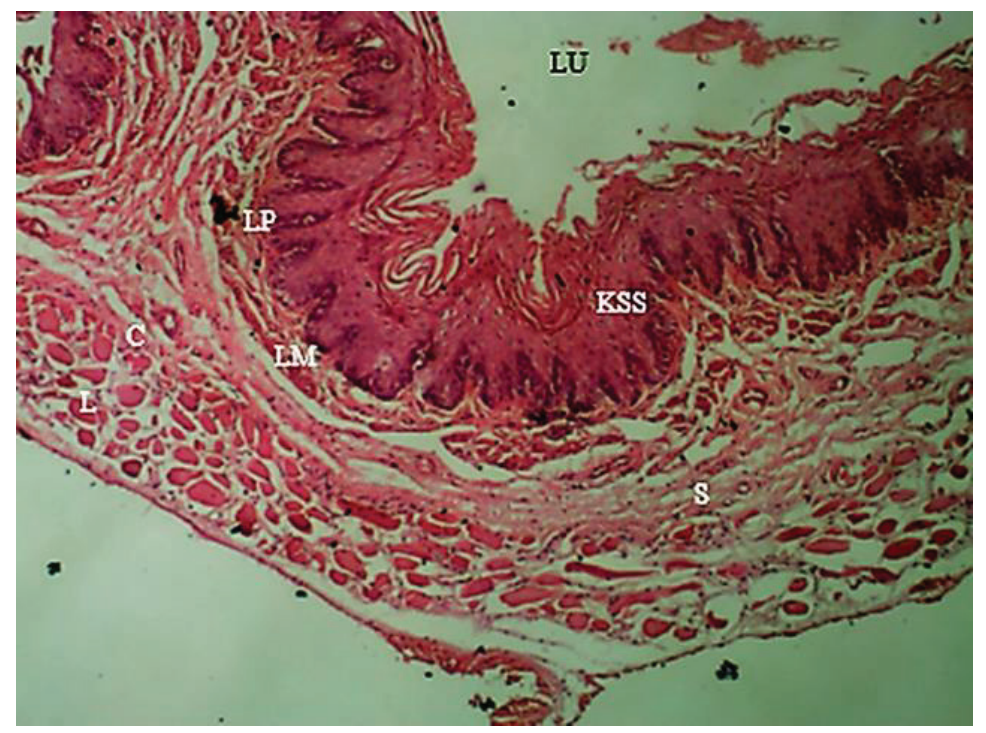

Fig (4): Photomicrograph of the oesophagus in African white breasted Hedgehog showing its lumen (LU), keratinized stratified squamous epithelium (KSS) of its lamina epithelialis mucosae; lamina propria (LP) and lamina muscularis mucosae (LM). The glandless submucosa (S) separated the mucosae from the tunica muscularis, which had an inner circular (C) and outer longitudinal (L) smooth and skeletal muscle bundles. H\&E X40.

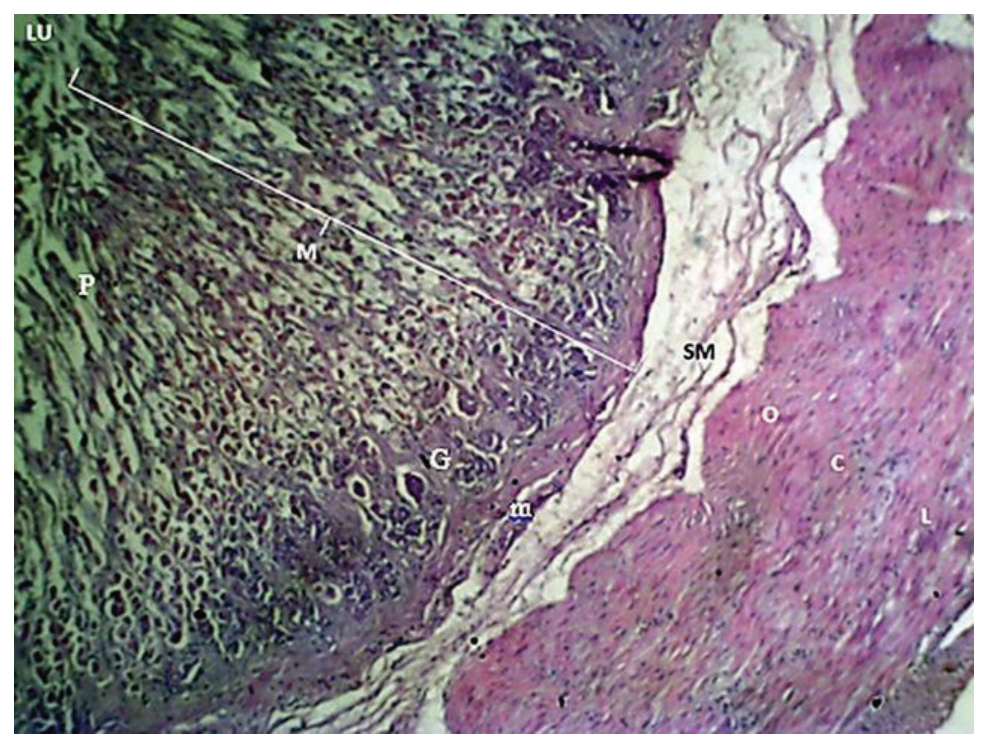

Fig (5): Photomicrograph of the stomach in African white breasted Hedgehog showing its lumen (LU), mucosa (M)), submucosa (SM), and the inner circular (O), middle oblique (C) and outer circular $(\mathrm{L})$ smooth muscle bundles layer of the tunica muscularis of its pyloric region. The mucosa was characterized by gastric pits $(P)$ that open into glands $(G)$ of the lamina propria. Lamina muscularis $(\mathrm{m})$ of the mucosa demarcates these glands from the submucosa. H\&E X 40. 


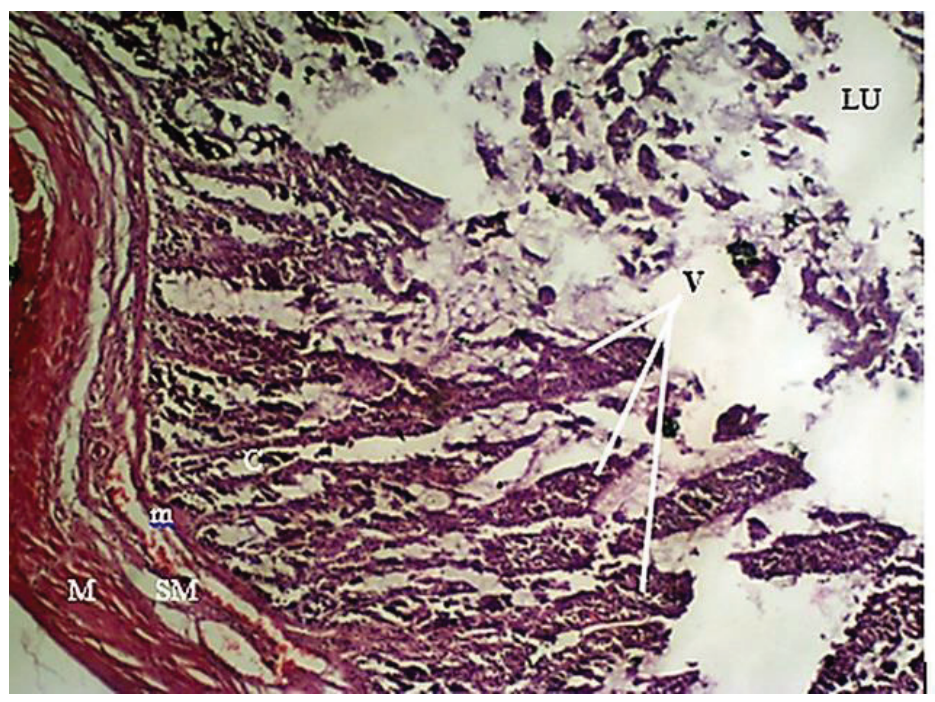

Fig (6): Photomicrograph of the duodenum in African white breasted Hedgehog showing its lumen (LU) and the villi (V), crypts of Lieberkuhn (C) and lamina muscularis (m) of its mucosa. This part of the submucosa (SM) shown was devoid of glands. The muscularis (M) had inner circular, middle oblique and outer circular smooth muscle bundles. H\&E X 40.

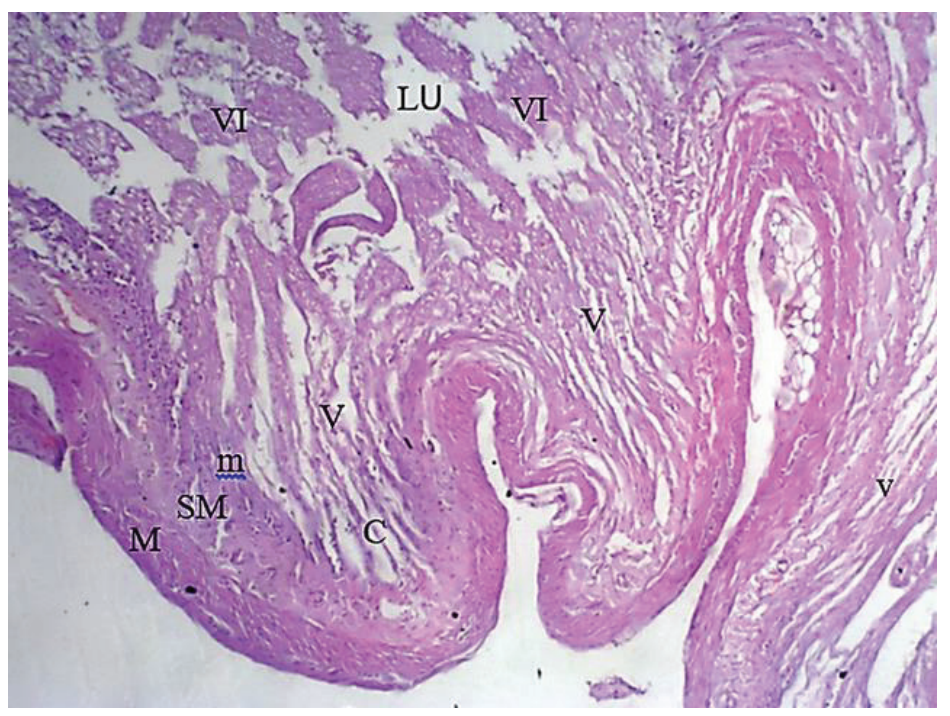

Fig (7): Photomicrograph of the jejunum in African white breasted Hedgehog showing its lumen (LU) and the relatively longer villi $(\mathrm{V})$ and their cut tips, islands (VI), crypts of Lieberkuhn $(\mathrm{C})$ and lamina muscularis $(\mathrm{m})$ of its mucosa. The submucosa (SM) devoid of glands. The muscularis had inner circular, middle oblique and outer circular smooth muscle bundles. H\&E X 40 . 


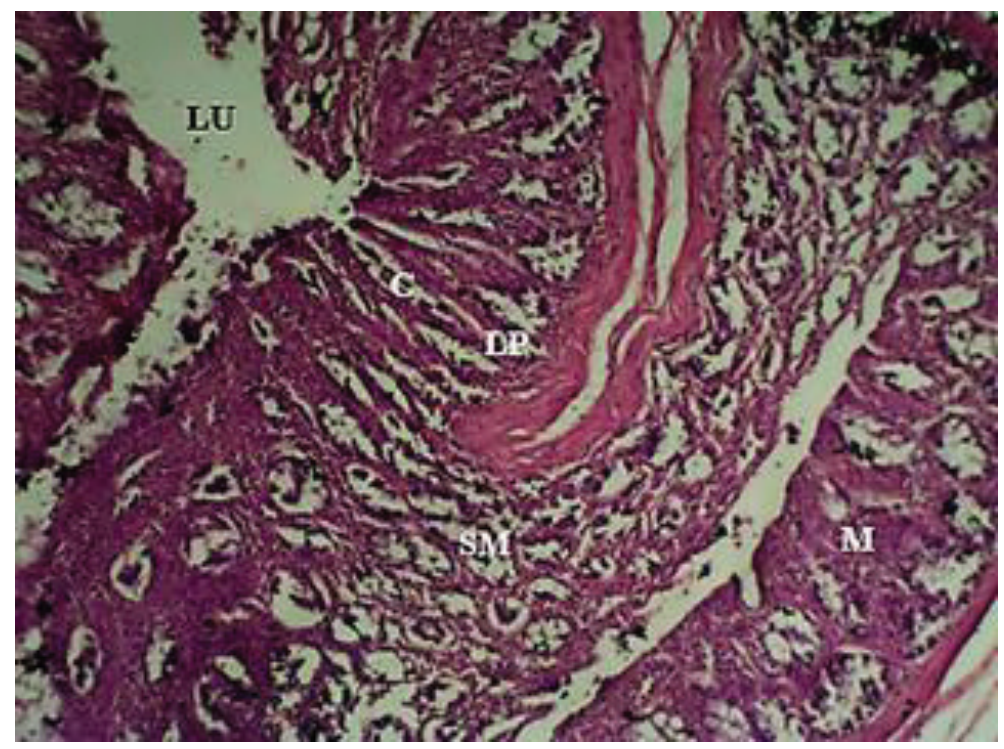

Fig (8): Photomicrograph of the colon in African white breasted Hedgehog showing its lumen (LU) and the crypts of Lieberkuhn (C), devoid of villi, and the lamina propria (LP) of its mucosa. The submucosa (SM) was quite extensive. The muscularis had inner circular, middle oblique and outer circular smooth muscle bundles. H\&E X 40. 


\section{Animal species in this Issue}

\section{Four-toed hedgehog (Atelerix albiventris)}

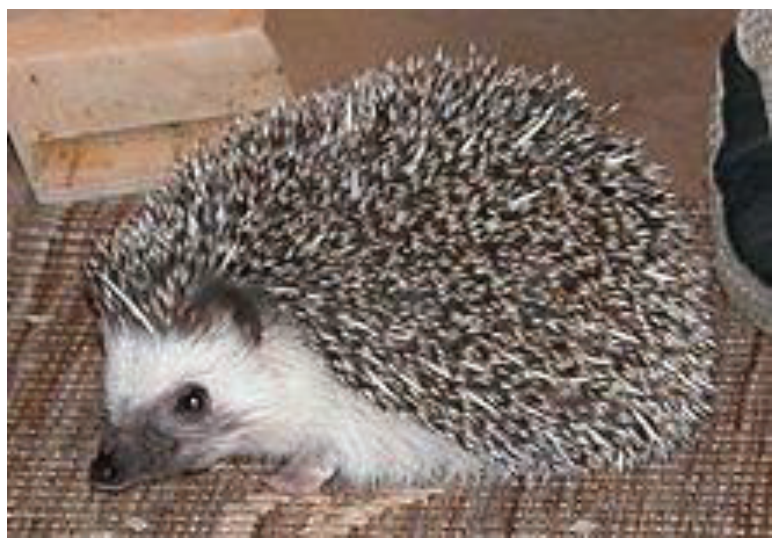

Kingdom: Animalia \& Phylum: Chordata \& Class: Mammalia \& Order: Eulipotyphla \&Family: Erinaceidae \&, Genus: Atelerix \& Species: A. albiventris

The four-toed hedgehog (Atelerix albiventris), is a species of hedgehog found throughout much of central and eastern Africa.

The four-toed hedgehog is a solitary, nocturnal animal. It generally moves along the ground, but is capable of both climbing and swimming when the need arises. It is highly energetic, sometimes covering miles of ground in a single night as it forages for insects, grubs, snails, spiders, some plant matter, and even small vertebrates. It has a high tolerance for toxins and has been recorded consuming scorpions and even venomous snakes.

The four-toed hedgehog is an oval bodied animal between 13 and $30 \mathrm{~cm}$ in length and weighing between 400 and 1,110 g. Females are typically larger than males. It has short legs, short tail typically around 2.5 centimeters in length, a long nose, and small beady eyes. The ears and whiskers are both relatively large, implying that the animal has good senses. As its common name implies, and unlike related species, the four-toed hedgehog typically only has 4 toes on each hind foot, lacking the hallux. However, in some individuals, a small bony lump may be present in place of the hallux, or there may even be a welldeveloped toe, especially on the hind feet. 